\title{
Dexmedetomidine-fentanyl versus propofol-fentanyl in flexible bronchoscopy: A randomized study
}

\author{
FENG YUAN, HONGGUANG FU, PENGJU YANG, KAI SUN, SHUBIAO WU, \\ MIAOMIAO LV, ZHENZHEN DONG and TIELI DONG
}

Department of Anesthesiology, Second Affiliated Hospital of Zhengzhou University, Zhengzhou, Henan 450014, P.R. China

Received January 10, 2015; Accepted February 18, 2016

DOI: $10.3892 /$ etm.2016.3274

\begin{abstract}
The aim of the present study was to evaluate the effect of a combination of dexmedetomidine and fentanyl on peripheral oxygen saturation $\left(\mathrm{SpO}_{2}\right)$ and hemodynamic stability in patients undergoing flexible bronchoscopy. One hundred patients undergoing elective flexible bronchoscopy were randomized into either a propofol-fentanyl group (PF group; $n=50$ ) or a dexmedetomidine-fentanyl group (DF group; $\mathrm{n}=50) . \mathrm{SpO}_{2}$ values, heart rate $(\mathrm{HR})$, systolic and diastolic blood pressure (SBP and DBP), patients' cough scores and discomfort scores as determined by patients and bronchoscopists, levels of sedation, number of times that additional lidocaine was required, elapsed time until recovery, and adverse events were recorded. The mean $\mathrm{SpO}_{2}$ values in the DF group were significantly higher than those in the PF group $(\mathrm{P}<0.01)$, and $\mathrm{HR}, \mathrm{SBP}$ and $\mathrm{DBP}$ were significantly lower in the DF group than in the PF group $(\mathrm{P}<0.05)$. There were no statistically significant differences between the two groups in terms of cough scores or discomfort scores, sedation levels, or number of times that additional lidocaine was required $(\mathrm{P}>0.05)$. Elapsed time until recovery in the $\mathrm{DF}$ group was significantly longer than in the PF group $(\mathrm{P}=0.002)$. The incidence of hypoxemia was significantly lower in the DF group than in the PF group ( $\mathrm{P}=0.027)$, but the incidence of bradycardia was significantly higher in the DF group than in the PF group $(\mathrm{P}=0.037)$. Dexmedetomidine-fentanyl was superior to propofol-fentanyl in providing satisfactory $\mathrm{SpO}_{2}$. Furthermore, dexmedetomidine-fentanyl attenuated hemodynamic responses during bronchoscopy and maintained hemodynamic stability in the early stage of the procedure.
\end{abstract}

Correspondence to: Dr Tieli Dong, Department of Anesthesiology, Second Affiliated Hospital of Zhengzhou University, 2 Jingba Road, Jinshui, Zhengzhou, Henan 450014, P.R. China

E-mail: tlddtl@126.com

Key words: flexible bronchoscopy, dexmedetomidine-fentanyl, propofol-fentanyl, peripheral oxygen saturation, hemodynamic stability, sedation

\section{Introduction}

Flexible bronchoscopy is commonly used for the diagnosis and management of a variety of pulmonary diseases. However, it is an invasive procedure that can induce coughing, pain, dyspnea and other adverse effects $(1,2)$. The use of sedatives not only can increase patients' safety and comfort (3) but also can make it easier for the bronchoscopist to perform the procedure and thus avoid extending its duration (4). In addition to alleviating the physiological response to airway irritation during the procedure (5), the proper sedatives should have a rapid onset and a short duration of action, in addition to allowing rapid recovery.

Propofol, a non-opioid and nonbarbiturate sedative hypnotic agent, is frequently used in the induction and maintenance of anesthesia. The properties of rapid onset and offset of action and of smooth recovery (6) make propofol an appealing agent alone or in combination with an opioid for procedural sedation (7-10). However, dose-dependent respiratory depression and hypoxemia are possible, owing to interactions and synergism between sedatives and opioids (11-13).

Dexmedetomidine, a highly selective $\alpha_{2}$-adrenoceptor agonist, has an affinity for $\alpha_{2}$-adrenoceptors that is 8 -fold greater than that of clonidine (14). In addition to providing sedative and analgesic effects (15), dexmedetomidine can be applied generally during fiberoptic intubation or other difficult airway procedures without respiratory depression (16-18). Research has revealed that dexmedetomidine alone is inferior to a combination of propofol and fentanyl for maintaining hemodynamic stability during endoscopic retrograde cholangiopancreatography (19). However, few data are available regarding the effectiveness of a combination of dexmedetomidine and fentanyl for bronchoscopy. Therefore, the present prospective, randomized study was conducted to test the hypothesis that dexmedetomidine-fentanyl is as effective as propofol-fentanyl for providing satisfactory peripheral oxygen saturation $\left(\mathrm{SpO}_{2}\right)$ and maintaining hemodynamic stability in patients undergoing flexible bronchoscopy.

\section{Materials and methods}

Patients. The study protocol was approved by the ethics committee of the Second Affiliated Hospital of Zhengzhou University (Zhengzhou, China), and it adhered to the principles 
of the Declaration of Helsinki. This study (registration number: ChiCTR-TRC-13003904) enrolled 100 patients undergoing flexible bronchoscopic procedures (for example, bronchoalveolar lavage or transbronchial biopsy) who provided written evidence of informed consent. The patients, whose ages ranged from 20 to 75 years (mean, 60.11 years) and who had an American Society of Anesthesiologists (ASA) physical status of I-III, received treatment at the Second Affiliated Hospital of Zhengzhou University at some point between December 2013 and May 2014. They were initially randomized to either of two groups, namely a propofol-fentanyl group (PF group; $n=50$ ) or a dexmedetomidine-fentanyl group (DF group; $n=50$ ), on the basis of a computer-generated randomization list. Exclusion criteria included the following items: Psychological disorders, hypersensitivity or allergy to the study drugs, uncontrolled hypertension (uncontrolled blood pressure $>140 / 90 \mathrm{mmHg}$ ), major abnormalities of liver function, ischemic heart disease and severe respiratory disease.

When patients arrived in the operating room, they underwent insertion of a peripheral intravenous cannula for fluid and drug administration. Their electrocardiograms and $\mathrm{SpO}_{2}$ were monitored continuously during the procedure, and blood pressure was automatically and noninvasively measured every $5 \mathrm{~min}$. At least $5 \mathrm{~min}$ prior to the initiation of fentanyl administration and during the entire bronchoscopic procedure, each patient received supplemental oxygen at a rate of $41 / \mathrm{min}$ via nasal cannula. When $\mathrm{SpO}_{2}$ was $<90 \%$ for $>30 \mathrm{sec}$, which was defined as oxygen desaturation or hypoxemia, oxygen delivery was increased to $6 \mathrm{l} / \mathrm{min}$ (20) and airway assistance maneuvers or devices were used, including verbal and tactile stimulation, chin lifts, jaw thrusts, a face mask and manual ventilation.

Flexible bronchoscopy. Any one of four experienced bronchoscopists used a bronchoscope of the same diameter to perform transnasal bronchoscopy in all patients, who were placed in a semi-recumbent position. Topical anesthesia was provided by spraying $2 \%$ lidocaine into the nasopharynx and oropharynx. In addition, 3-ml aliquots of $1 \%$ lidocaine were sprayed over the vocal cords, onto the trachea, and onto the right and left main bronchi. Supplemental local anesthesia was given as deemed necessary by the bronchoscopist. No inhaled lidocaine was administered prior to the procedure (21).

Propofol was infused in a target-controlled manner. However, to guarantee the patients' safety, a dose of $1 \mu \mathrm{g} / \mathrm{kg}$ dexmedetomidine was used for at least the initial $10 \mathrm{~min}$, and then a continuous intravenous infusion rate of $0.2-0.7 \mu \mathrm{g} / \mathrm{kg} / \mathrm{h}$ was used, which is in line with the guidelines set forth in 1999 by the US Food and Drug Administration (22).

Before starting sedation, patients in both groups received an infusion dose of $1 \mu \mathrm{g} / \mathrm{kg}$ fentanyl (batch no. 1130506; Yichang Humanwell Pharmaceutical Co., Ltd., Yichang, China). Thereafter, the patients in the DF group received a loading dose of $1 \mu \mathrm{g} / \mathrm{kg}$ dexmedetomidine (batch no. 13031516: Jiangsu Hengrui Medicine Co., Ltd., Jiangsu, China), infused continuously for $\sim 12 \mathrm{~min}$, and the loading dose was followed by a continuous intravenous infusion at a rate of $0.5 \mu \mathrm{g} / \mathrm{kg} / \mathrm{h}$ (23). The three-compartment pharmacokinetic model was used, with the infusion of propofol administered via a target-controlled syringe infusion pump (Injectomat TIVA Agilia; Fresenius Kabi, Paris, France), according to
Table I. Modified Observer's Assessment of Alertness/Sedation scale (MOAA/S).

\begin{tabular}{lc} 
Responsiveness & Score \\
\hline Agitated & 6 \\
Responds readily to name spoken in normal tone & 5 \\
Lethargic response to name spoken in normal tone & 4 \\
Responds only after name is called loudly and/or & \\
repeatedly & 3 \\
Responds only after mild prodding or shaking & 2 \\
Does not respond to mild prodding or shaking & 1 \\
Does not respond to deep stimulus & 0
\end{tabular}

Reproduced with permission from Drake et al (25).

each patient's age and weight. The initial effect-site target for propofol (batch no. JV642; AstraZeneca, Basiglio, Italy) concentration was $4 \mu \mathrm{g} / \mathrm{ml}$ in the PF group. Subsequently, the concentration of propofol was maintained at a level between 2 and $4 \mu \mathrm{g} / \mathrm{ml}$ (24) during the 12-min infusion period. Loading doses of dexmedetomidine or propofol were observed to achieve adequate conscious sedation, indicated by the onset of ptosis. Whenever indications of insufficient sedation were observed, including signs of pain or discomfort, agitation, a persistent cough, and inadequate motor or verbal response to manipulation, an additional $2 \mathrm{ml}$ of $2 \%$ lidocaine was administered into the trachea through the side hole of a flexible bronchoscope. The number of times that additional lidocaine was administered was recorded.

Outcome variables. The primary study objectives were the mean $\mathrm{SpO}_{2}$ and hemodynamic variables. During the procedure, the $\mathrm{SpO}_{2}$ and hemodynamic variables, including heart rate (HR), systolic blood pressure (SBP) and diastolic blood pressure (DBP), were recorded for both groups at the following time points: $1 \mathrm{~min}$ before initiation of fentanyl administration $\left(\mathrm{T}_{1}\right)$, at the initiation of flexible bronchoscopy $\left(\mathrm{T}_{2}\right), 1 \mathrm{~min}$ after initiation of bronchoscopy $\left(\mathrm{T}_{3}\right), 5$ min after initiation of bronchoscopy $\left(\mathrm{T}_{4}\right)$ and at the end of bronchoscopy $\left(\mathrm{T}_{5}\right)$.

Secondary objectives were cough scores and discomfort scores as assessed by the patients themselves and also by the bronchoscopists. At the end of the procedure, bronchoscopists were asked to record their perception of the patient's cough during the procedure, using a 10-point visual analog scale (VAS) on which 0 represented no cough and 10 represented incessant coughing. Two hours after bronchoscopy, patients were asked to record their perception of their own coughing associated with the procedure, using the same 10-point VAS. Patients and bronchoscopists were asked to use a 10-point VAS to rate patients' discomfort associated with the procedure, where 0 represented no discomfort and 10 represented the greatest possible discomfort. Willingness to undergo repeat bronchoscopy was also recorded.

The level of sedation was assessed at $\mathrm{T}_{2}$ and $\mathrm{T}_{4}$ using the Modified Observer's Assessment of Alertness/Sedation (MOAA/S) scale, detailed in Table I (25). Indications for flexible bronchoscopy, type of bronchoscopy, duration of 
Table II. Demographic and baseline characteristics of patients undergoing flexible bronchoscopy.

\begin{tabular}{lrr}
\hline Characteristic & DF group $(\mathrm{n}=50)$ & PF group (n=50) \\
\hline Age, years & $59.76 \pm 7.61$ & $60.46 \pm 6.93$ \\
Male/female $(\%)$ & $27 / 23(54 / 46)$ & $22 / 28(44 / 56)$ \\
Body mass index, $\mathrm{kg} / \mathrm{m}^{2}$ & $22.20 \pm 3.06$ & $21.69 \pm 3.16$ \\
ASA class & & $20(40)$ \\
I & $22(44)$ & $16(32)$ \\
II & $13(26)$ & $14(28)$ \\
III & $15(30)$ & $9(18)$ \\
Comorbidities & & $8(16)$ \\
Chronic obstructive pulmonary disease & $7(14)$ & $10(20)$ \\
Coronary artery disease & $10(20)$ & $12(24)$ \\
Diabetes & &
\end{tabular}

Values are presented as mean \pm standard deviation, or number (\%) of patients. DF group, dexmedetomidine-fentanyl group; PF group, propofol-fentanyl group. ASA, American Society of Anesthesiologists.

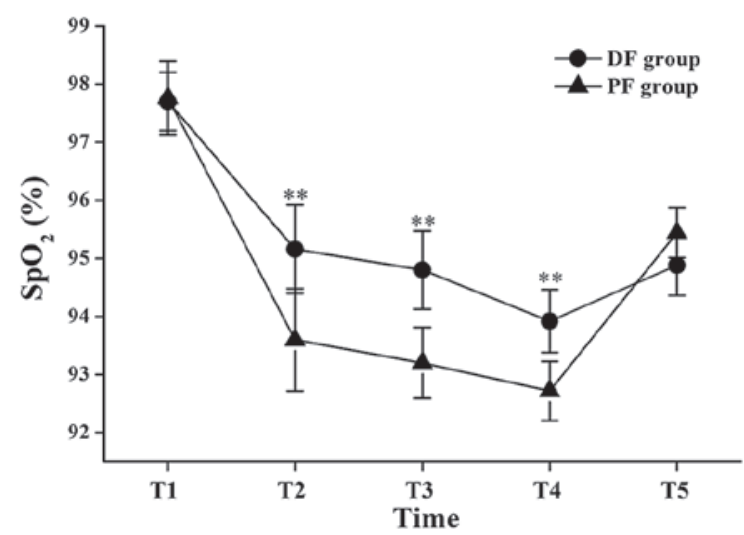

Figure 1. Changes in peripheral oxygen saturation $\left(\mathrm{SpO}_{2}\right)$ during flexible bronchoscopy. Data are shown as mean \pm standard deviation. $\mathrm{T}_{1}, 1 \mathrm{~min}$ before initiation of fentanyl administration; $\mathrm{T}_{2}$, at initiation of flexible bronchoscopy; $\mathrm{T}_{3}, 1 \mathrm{~min}$ after initiation of bronchoscopy; $\mathrm{T}_{4}, 5 \mathrm{~min}$ after initiation of bronchoscopy; $\mathrm{T}_{5}$, at the end of bronchoscopy; $\mathrm{DF}$ group, dexmedetomidine-fentanyl group; PF group, propofol-fentanyl group. ${ }^{* *} \mathrm{P}<0.01$ vs. the $\mathrm{PF}$ group.

procedure, and elapsed time until recovery were recorded for all patients. Recovery time was defined as the time (min) elapsed between withdrawal of a flexible bronchoscope and the moment that the patient was fully awake and conversant.

Adverse events. Hypotension (SBP $<90 \mathrm{mmHg}$ or mean arterial pressure $<60 \mathrm{mmHg}$ ) was treated with an infusion of $10 \mathrm{mg}$ ephedrine. Bradycardia (HR $<60$ beats/min) was treated with an infusion of $0.3 \mathrm{mg}$ atropine. Hypertension (SBP $>180 \mathrm{~mm}$ $\mathrm{Hg}$ or DBP $>100 \mathrm{~mm} \mathrm{Hg}$ ) and tachycardia (HR $>100$ beats/min and/or variation of $>20 \%$ from baseline value) were treated by administering an additional $2 \mathrm{ml}$ of $2 \%$ lidocaine into the trachea.

Statistical analysis. In a large study, Grendelmeier et al investigated the safety of sedation with propofol in flexible bronchoscopy and reported a mean $\mathrm{SpO}_{2}$ of $93 \%$ [standard deviation (SD), 4.3\%] in their propofol group (26). For the present smaller study, it was determined that a sample size of 44 participants per group was necessary for a two-sided significance level $(\alpha)$ of 0.05 and a power of 0.9 to detect a $3 \%$ difference in the mean $\mathrm{SpO}_{2}$ between the two groups. Assuming a $10 \%$ dropout rate, the actual size needed for each group was 50 participants. The formula used to calculate the sample size that was required was the following: $\mathrm{n}=2[(\mu \alpha / 2+\mu \beta) \sigma / \delta]^{2}$, in which $\delta=3, \sigma=4.3, \alpha=0.05$ and $\beta=0.1$. According to the $\mu$ value table, $\mu_{0.05 / 2}=1.96$ and $\mu_{0.1}=1.282$, which were added into the formula $(\mathrm{n}=44)$.

The data are presented as mean $\pm \mathrm{SD}$, or as number with the percentage of patients in parentheses. Repeated-measures analysis of variance was used to test between-group differences in $\mathrm{SpO}_{2}, \mathrm{HR}, \mathrm{SBP}$ and DBP over time. Continuous outcomes were analyzed with the Student's t-test or the Mann-Whitney $\mathrm{U}$ test as appropriate in terms of data distribution. Categorical data were examined with the $\chi^{2}$ test, Fisher's exact test, or Mann-Whitney U test as appropriate. Statistical analyses were performed using the Statistical Package for Social Sciences (SPSS for Windows, version 18.0; SPSS, Inc., Chicago, IL, USA). A P-value of $<0.05$ was considered statistically significant.

\section{Results}

Comparison of basic patient characteristics, indications for flexible bronchoscopy, and type or duration of procedure in the two groups. There were no significant differences between the DF and PF groups in terms of age, presence of comorbidities, or ASA physical status (Table II). There were also no statistically significant differences between the two groups regarding the indications for bronchoscopy, type of bronchoscopy, and procedure duration (Table III).

Changes in $\mathrm{SpO}_{2}$. There were no significant differences in $\mathrm{SpO}_{2}$ values between the two groups at T1 and T5; however, the mean $\mathrm{SpO}_{2}$ values at the T2, T3 and T4 time points in 
Table III. Indications for flexible bronchoscopy and type and duration of procedure.

\begin{tabular}{lrr}
\hline Bronchoscopy parameter & DF group $(\mathrm{n}=50)$ & PF group $(\mathrm{n}=50)$ \\
\hline Indication for bronchoscopy & & $13(26)$ \\
Infection & $9(18)$ & $11(22)$ \\
Hemoptysis & $20(40)$ & $18(36)$ \\
Suspicion of malignancy & $8(16)$ & $10(20)$ \\
Others & & $17(34)$ \\
Type of bronchoscopy & $15(30)$ & $9(18)$ \\
Inspection & $10(20)$ & $16(32)$ \\
Bronchoalveolar lavage & $18(36)$ & $8(16)$ \\
Transbronchial biopsy & $7(14)$ & $21.14 \pm 1.87$ \\
Others & $20.64 \pm 2.08$ & \\
Duration of procedure, min & &
\end{tabular}

Values are presented as mean \pm standard deviation, or number $(\%)$ of patients. DF group, dexmedetomidine-fentanyl group; PF group, propofol-fentanyl group.

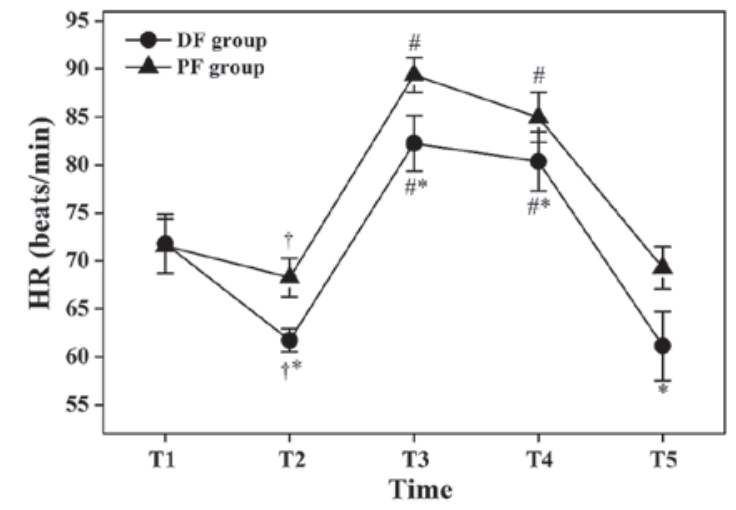

Figure 2. Changes in heart rate (HR) during flexible bronchoscopy. Data are shown as mean \pm standard deviation. $\mathrm{T}_{1}, 1 \mathrm{~min}$ before initiation of fentanyl administration; $\mathrm{T}_{2}$, at initiation of flexible bronchoscopy; $\mathrm{T}_{3}, 1 \mathrm{~min}$ after initiation of bronchoscopy; $\mathrm{T}_{4}, 5 \mathrm{~min}$ after initiation of bronchoscopy; $\mathrm{T}_{5}$, at the end of bronchoscopy; DF group, dexmedetomidine-fentanyl group; PF group, propofol-fentanyl group. ${ }^{*} \mathrm{P}<0.05$ vs. the $\mathrm{PF}$ group; ${ }^{\dagger} \mathrm{P}<0.05$ vs. $\mathrm{T}_{1}$ in the same group; ${ }^{\#} \mathrm{P}<0.05$ vs. $\mathrm{T}_{2}$ in the same group.

the DF group were significantly higher than those in the PF group $(95.16 \pm 2.38$ vs. $93.6 \pm 2.63 \%$ at $\mathrm{T} 2$ : $\mathrm{P}<0.01 ; 94.8 \pm 2.05$ vs. $93.2 \pm 1.83 \%$ at $\mathrm{T} 3: \mathrm{P}<0.01 ; 93.92 \pm 1.64$ vs. $92.72 \pm 1.6 \%$ at T4: $\mathrm{P}<0.01$; Fig. 1).

Changes in hemodynamic variables. The HR values at T2 were significantly lower compared with those at $\mathrm{T} 1$ in the same group $(\mathrm{P}<0.05$; Fig. 2$)$, but the HR values at $\mathrm{T} 3$ and $\mathrm{T} 4$ were significantly higher compared with those at T2 in the same group $(\mathrm{P}<0.05$; Fig. 2$)$. The HR values of the $\mathrm{DF}$ group at T2, T3, T4 and T5 were significantly lower compared with those of the PF group $(61.72 \pm 3.6$ vs. $68.28 \pm 5.94$ beats $/ \mathrm{min}$ at T2: $\mathrm{P}<0.05 ; 82.24 \pm 8.7$ vs. $89.36 \pm 5.68$ beats $/ \mathrm{min}$ at $\mathrm{T} 3$ : $\mathrm{P}<0.05 ; 80.36 \pm 9.26$ vs. $84.96 \pm 8.06$ beats $/ \mathrm{min}$ at $\mathrm{T} 4: \mathrm{P}<0.05$; $61.14 \pm 11.06$ vs. $69.28 \pm 6.53$ beats $/ \mathrm{min}$ at T5: $\mathrm{P}<0.05$; Fig. 2 ).

The SBP values at T2 were significantly lower compared with those at $\mathrm{T} 1$ in the same group $(\mathrm{P}<0.05$; Fig. 3), and the SBP values at $\mathrm{T} 3$ were significantly higher compared with those at

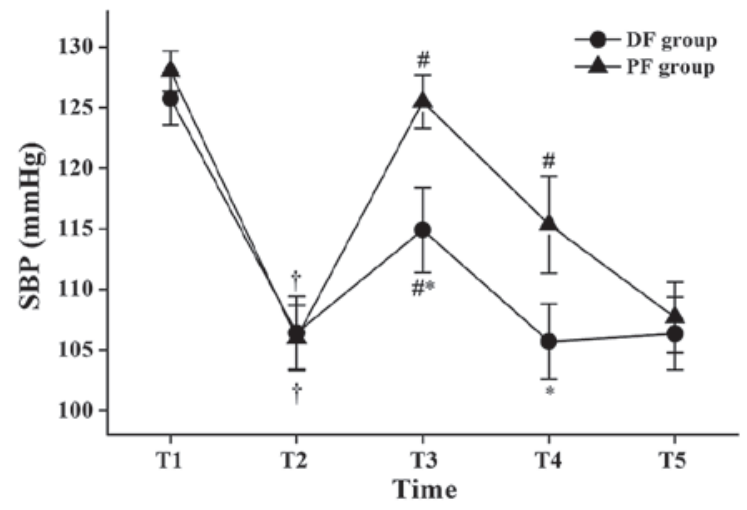

Figure 3. Changes in systolic blood pressure (SBP) during flexible bronchoscopy. Data are shown as mean \pm standard deviation. $\mathrm{T}_{1}, 1 \mathrm{~min}$ before initiation of fentanyl administration; $\mathrm{T}_{2}$, at initiation of flexible bronchoscopy; $\mathrm{T}_{3}$, $1 \mathrm{~min}$ after initiation of bronchoscopy; $\mathrm{T}_{4}, 5 \mathrm{~min}$ after initiation of bronchoscopy; $\mathrm{T}_{5}$, at the end of bronchoscopy; DF group, dexmedetomidine-fentanyl group; PF group, propofol-fentanyl group. ${ }^{*} \mathrm{P}<0.05$ vs. the $\mathrm{PF}$ group; ${ }^{\dagger} \mathrm{P}<0.05$ vs. $\mathrm{T}_{1}$ in the same group; ${ }^{\prime \prime} \mathrm{P}<0.05$ vs. $\mathrm{T}_{2}$ in the same group.

T2 in the same group $(\mathrm{P}<0.05$; Fig. 3$)$. In the PF group, the SBP values at $\mathrm{T} 4$ were significantly higher compared with those at T2 ( $<<0.05$; Fig. 3). The SBP values of the DF group were significantly lower compared with those of the PF group at $\mathrm{T} 3$ and T4 (114.92 \pm 10.66 vs. $125.52 \pm 6.65 \mathrm{mmHg}$ at $\mathrm{T} 3: \mathrm{P}<0.05$; $105.72 \pm 9.29$ vs. $115.36 \pm 11.9 \mathrm{mmHg}$ at $\mathrm{T} 4$ : $\mathrm{P}<0.05$, Fig. 3 ).

The DBP values at T2 were significantly lower compared with those at $\mathrm{T} 1$ in the same group ( $\mathrm{P}<0.05$; Fig. 4$)$, and the $\mathrm{DBP}$ values at $\mathrm{T} 3$ and $\mathrm{T} 4$ were significantly higher compared with those at $\mathrm{T} 2$ in the same group $(\mathrm{P}<0.05$; Fig. 4$)$. The DBP values of the DF group at T3 and T4 compared with those of the PF group were statistically lower $(80.36 \pm 9.26$ vs. $86.36 \pm 5.77 \mathrm{mmHg}$ at $\mathrm{T} 3: \mathrm{P}<0.05 ; 75.98 \pm 5.27$ vs. 79.44 $\pm 6.64 \mathrm{mmHg}$ at T4: $\mathrm{P}<0.05$; Fig. 4).

VAS scores, additional lidocaine administration, MOAA/S scores and recovery times. There were no significant differences in VAS scores for coughing and discomfort between the 
Table IV. Outcome parameters in patients randomized to dexmedetomidine-fentanyl or propofol-fentanyl.

\begin{tabular}{lcc}
\hline Outcome parameter & DF group $(\mathrm{n}=50)$ & PF group $(\mathrm{n}=50)$ \\
\hline No. of times additional lidocaine was required & & 20 \\
0 & 22 & 16 \\
1 & 13 & 14 \\
$>2$ & 15 & 0.802 \\
MOAA/S score 5/4/3/2/1/0 & & $0.7 / 6 / 37 / 0 / 0$ \\
$\mathrm{~T}_{2}$ & $0 / 5 / 10 / 35 / 0 / 0$ & $12 / 23 / 8 / 7 / 0 / 0$ \\
$\mathrm{~T}_{4}$ & $15 / 24 / 6 / 5 / 0 / 0$ & $11.91 \pm 2.14$ \\
Recovery time, $\min$ & $13.1 \pm 1.68^{\mathrm{a}}$ & 0.808 \\
\hline
\end{tabular}

Values are presented as mean \pm standard deviation, or number of patients. The MOAA/S scale ranges from 5 (alert) to 0 (asleep). MOAA/S, Modified Observer's Assessment of Alertness/Sedation; DF group, dexmedetomidine-fentanyl group; PF group, propofol-fentanyl group. ${ }^{a} \mathrm{P}<0.05$ vs. the $\mathrm{PF}$ group.

Table V. Adverse events during the procedure.

\begin{tabular}{|c|c|c|c|}
\hline Adverse event or parameter & DF group $(n=50)$ & $P F$ group $(n=50)$ & P-value \\
\hline Bradycardia & $13(26)^{\mathrm{a}}$ & $5(10)$ & 0.037 \\
\hline Tachycardia & $6(12)$ & $8(16)$ & 0.564 \\
\hline Hypotension & $8(16)$ & $5(10)$ & 0.372 \\
\hline Hypertension & $5(10)$ & $7(14)$ & 0.538 \\
\hline Hypoxemia & $1(2)^{\mathrm{a}}$ & $7(14)$ & 0.027 \\
\hline Willingness for repeat of bronchoscopy & $38(76)$ & $33(66)$ & 0.271 \\
\hline
\end{tabular}

Values are presented as number (\%) of patients. DF group, dexmedetomidine-fentanyl group; PF group, propofol-fentanyl group. ${ }^{\mathrm{P}}<0.05$ vs the PF group.

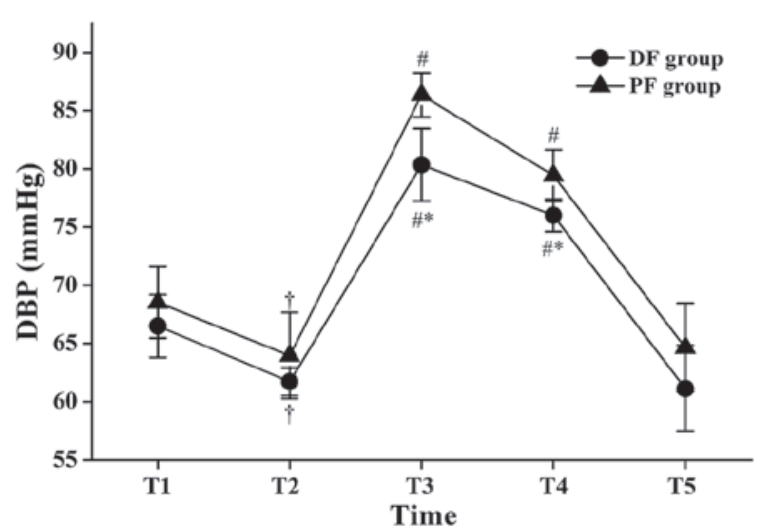

Figure 4. Changes in diastolic blood pressure (DBP) during flexible bronchoscopy. Data are presented as mean \pm standard deviation. $\mathrm{T}_{1}, 1 \mathrm{~min}$ before initiation of fentanyl administration; $\mathrm{T}_{2}$, at initiation of flexible bronchoscopy; $\mathrm{T}_{3}, 1 \mathrm{~min}$ after initiation of bronchoscopy; $\mathrm{T}_{4}, 5 \mathrm{~min}$ after initiation of bronchoscopy; $\mathrm{T}_{5}$, at the end of bronchoscopy; DF group, dexmedetomidine-fentanyl group; PF group, propofol-fentanyl group. ${ }^{*} \mathrm{P}<0.05$ vs. the $\mathrm{PF}$ group; ${ }^{\dagger} \mathrm{P}<0.05$ vs. $\mathrm{T}_{1}$ in the same group; ${ }^{\text {}} \mathrm{P}<0.05$ vs. $\mathrm{T}_{2}$ in the same group.

two groups as rated by patients or by bronchoscopists (Fig. 5). There was also no significant difference between groups regarding the number of times that additional lidocaine was necessary. There was no significant difference between groups
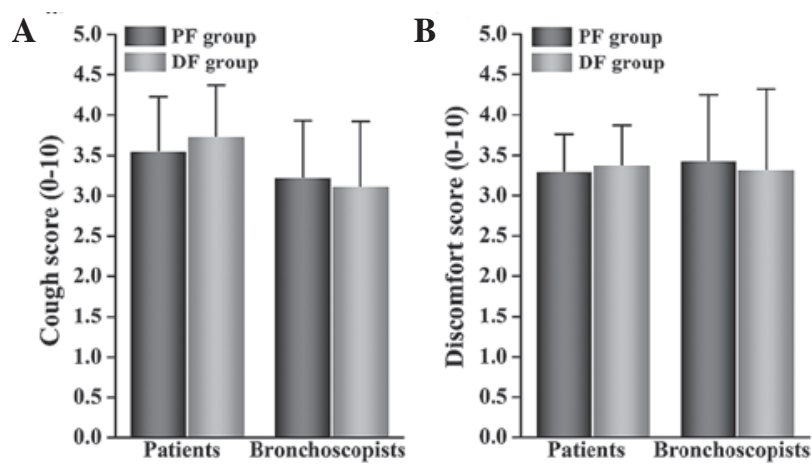

Figure 5. Patients' (A) cough and (B) discomfort scores, as assessed by patients and bronchoscopists. Data shown are mean \pm standard deviation. DF group, dexmedetomidine-fentanyl group; PF group, propofol-fentanyl group.

regarding MOAA/S scores at T2 and T4. The recovery times for the DF group were significantly longer than those for the $\mathrm{PF}$ group (13.1 \pm 1.68 vs. $11.91 \pm 2.14$ min: $\mathrm{P}<0.05$; Table IV).

Adverse events. There were no significant differences in hypotension, hypertension, tachycardia, or the proportions of patients who would be willing to repeat the bronchoscopy procedure between the two groups. However, there was a statistically significant difference in the number of cases of 
hypoxemia between the DF and PF groups ( 1 and 7 cases, respectively: $\mathrm{P}<0.05$; Table $\mathrm{V})$. Furthermore, there was a significant difference in bradycardia between the DF and PF groups (13 and 5 cases, respectively: $\mathrm{P}<0.05$; Table V).

\section{Discussion}

The results of the present study show that a combination of dexmedetomidine and fentanyl is superior to a combination of propofol and fentanyl, the reasons for which are discussed below.

A variety of sedatives, including benzodiazepines, opioids and propofol, have been used for bronchoscopy. However, certain studies have shown that following the use of sedatives, recovery times are longer and more desaturations occur $(27,28)$. Although dexmedetomidine produces sedative, analgesic and hypnotic affects, unlike other sedatives it provides respiratory stability and does not cause any clinically relevant respiratory depression (29). This finding has also been confirmed by further research, which showed that dexmedetomidine safely produces satisfactory sedation during fiberoptic intubation or other difficult airway procedures (16-18,30). Moreover, dexmedetomidine has no effect on end-tidal carbon dioxide (31), preserves better arterial saturation (32) and improves oxygenation (33).

In the present study, the incidence of hypoxemia in the patients treated with dexmedetomidine was much lower than in the patients treated with propofol. This is in agreement with the results of a study by Liao et al (34). This trend has previously been explained as being due to the addition of an opioid to propofol resulting in oxygen desaturation in patients undergoing bronchoscopic procedures (35).

According to a study by Adachi et al, hemodynamic responses during flexible bronchoscopy reflect an increase in HR and blood pressure (36). In the present study, a greater increase in HR and blood pressure at initiation of bronchoscopy were observed among patients who were given propofol compared with those who were given dexmedetomidine. These findings show that a combination of dexmedetomidine and fentanyl is superior to a combination of propofol and fentanyl in attenuating hemodynamic responses during flexible bronchoscopy and that specifically, the former combination maintained hemodynamic stability in the early stage of the procedure. This was a better result than that reported by Ryu et al for a dexmedetomidine group compared with a remifentanil group during flexible bronchoscopy (37); they found no differences between outcomes for those two sedatives.

Notably, VAS scores for patients' coughing and discomfort, as recorded by patients and bronchoscopists were no different between the dexmedetomidine and propofol groups. These results differed from those of He et al (38) and Hendrickx et al (39) who found that dexmedetomidine had a less pronounced amnesic effect, which might have occurred because dexmedetomidine interacted synergistically with fentanyl to produce deep hypnosis $(38,39)$. This might also explain why dexmedetomidine was associated with a longer recovery time. However, on the basis of the present research methodology, the current study focused on numbers of patients who were given additional lidocaine two or more times. The exact amount of lidocaine administered was not recorded. As a result, whether the total amount of additional lidocaine correlated with the effects of propofol or dexmedetomidine administration was not determined; thus, it is not possible to directly draw conclusions regarding the influence of propofol compared with dexmedetomidine on cough and discomfort scores. Therefore, the amount of lidocaine spray used should be recorded in future investigations.

The main adverse effects of dexmedetomidine include bradycardia, hypotension, and hypertension (40). Bradycardia was observed more often in the dexmedetomidine group than in the propofol group. Although the two groups displayed both hypotension and hypertension, the incidence of these conditions did not differ between groups.

The present study had the following limitations. First, it was not a blinded study. Patients' level of sedation was assessed by MOAA/S at only two time points during flexible bronchoscopy. That might have influenced the results. To remove sedation level as a confounding factor in future studies, depth of anesthesia should be assessed by monitoring equipment at additional time points, along with mean $\mathrm{SpO}_{2}$ values and hemodynamic variables. Second, aside from bradycardia, hypotension and hypertension, other adverse effects of dexmedetomidine that have been observed in other studies, such as delirium, nausea, vomiting, and shivering, were not recorded. Future studies must address those additional effects.

In conclusion, with the exception of a longer recovery time and higher incidence of bradycardia, the present study found that dexmedetomidine-fentanyl was superior to propofol-fentanyl in providing satisfactory sedation and peripheral oxygen saturation during flexible bronchoscopy. Furthermore, dexmedetomidine-fentanyl attenuated hemodynamic responses and maintained hemodynamic stability in the early stage of bronchoscopy.

\section{Acknowledgements}

Katharine O'Moore-Klopf, ELS (East Setauket, NY, USA) provided professional English-language editing of this article.

\section{References}

1. Poi PJ, Chuah SY, Srinivas P and Liam CK: Common fears of patients undergoing bronchoscopy. Eur Respir J 11: 1147-1149, 1998.

2. Xavier Scheuermeyer F, Andolfatto G, Qian H and Grafstein E: Does the sedation regimen affect adverse events during procedural sedation and analgesia in injection drug users? CJEM 15: 279-288, 2013.

3. Putinati S, Ballerin L, Corbetta L, Trevisani L and Potena A: Patient satisfaction with conscious sedation for bronchoscopy. Chest 115: 1437-1440, 1999.

4. Du Rand IA, Blaikley J, Booton R, Chaudhuri N, Gupta V, Khalid S, Mandal S, Martin J, Mills J, Navani N, et al: British Thoracic Society guideline for diagnostic flexible bronchoscopy in adults.. Thorax 68 (Suppl 1): i1-i44, 2013.

5. Davies L, Mister R, Spence DP, Calverley PM, Earis JE and Pearson MG: Cardiovascular consequences of fibreoptic bronchoscopy. Eur Respir J 10: 695-698, 1997.

6. Alletag MJ, Auerbach MA and Baum CR: Ketamine, propofol and ketofol use for pediatric sedation. Pediatr Emerg Care 28: 1391-1395, 2012.

7. Berkenbosch JW, Graff GR, Stark JM, Ner Z and Tobias JD: Use of a remifentanil-propofol mixture for pediatric flexible fiberoptic bronchoscopy sedation. Pediatric Anesthesia 14: 941-946, 2004. 
8. Clark G, Licker M, Younossian AB, Soccal PM, Frey JG Rochat T, Diaper J, Bridevaux PO and Tschopp JM: Titrated sedation with propofol or midazolam for flexible bronchoscopy: A randomised trial. Eur Respir J 34: 1277-1283, 2009.

9. Reyle-Hahn M, Niggemann B, Max M, Streich R and Rossaint R: Remifentanil and propofol for sedation in children and young adolescents undergoing diagnostic flexible bronchoscopy. Paediatr Anaesth 10: 59-63, 2000

10. Stolz D, Kurer G, Meyer A, Chhajed PN, Pflimlin E, Strobel W and Tamm M: Propofol vs. combined sedation in flexible bronchoscopy: A randomised non-inferiority trial. Eur Respir J 34 1024-1030, 2009.

11. Kodaka M, Okamoto Y, Handa F, Kawasaki J and Miyao H: Relation between fentanyl dose and predicted $\mathrm{EC}_{50}$ of propofol for laryngeal mask insertion. Br J Anaesth 92: 238-241, 2004.

12. Peacock JE, Luntley JB, O'Connor B, Reilly CS, Ogg TW, Watson BJ and Shaikh S: Remifentanil in combination with propofol for spontaneous ventilation anaesthesia. $\mathrm{Br}$ Anaesth 80: 509-511, 1998

13. Xu J, Yao Z, Li S and Chen L: A non-tracheal intubation (tubeless) anesthetic technique with spontaneous respiration for upper airway surgery. Clin Invest Med 36: E151-E157, 2013.

14. Hammer GB, Drover DR, Cao H, Jackson E, Williams GD, Ramamoorthy C, Van Hare GF, Niksch A and Dubin AM: The effects of dexmedetomidine on cardiac electrophysiology in children. Anesth Analg 106: 79-83, 2008.

15. Tan JA and Ho KM: Use of dexmedetomidine as a sedative and analgesic agent in critically ill adult patients: A meta-analysis. Intensive Care Med 36: 926-939, 2010.

16. Bergese SD, Khabiri B, Roberts WD, Howie MB, McSweeney TD and Gerhardt MA: Dexmedetomidine for conscious sedation in difficult awake fiberoptic intubation cases. J Clin Anesth 19: 141-144, 2007.

17. Ramsay MA and Luterman DL: Dexmedetomidine as a total intravenous anesthetic agent. Anesthesiology 101: 787-790, 2004

18. Stamenkovic DM and Hassid M: Dexmedetomidine for fiberoptic intubation of a patient with severe mental retardation and atlantoaxial instability. Acta Anaesthesiol Scand 50: 1314-1315, 2006.

19. Muller S, Borowics SM, Fortis EA, Stefani LC, Soares G, Maguilnik I, Breyer HP, Hidalgo MP and Caumo W: Clinical efficacy of dexmedetomidine alone is less than propofol for conscious sedation during ERCP. Gastrointest Endosc 67: 651-659, 2008

20. Chhajed PN and Glanville AR: Management of hypoxemia during flexible bronchoscopy. Clin Chest Med 24: 511-516, 2003

21. Wahidi MM, Jain P, Jantz M, Lee P, Mackensen GB, Barbour SY, Lamb C and Silvestri GA: American College of Chest Physicians consensus statement on the use of topical anesthesia, analgesia and sedation during flexible bronchoscopy in adult patients. Chest 140: 1342-1350, 2011.

22. Panzer O, Moitra V and Sladen RN: Pharmacology of sedative-analgesic agents: Dexmedetomidine, remifentanil, ketamine, volatile anesthetics and the role of peripheral mu antagonists. Crit Care Clin 25: 451-469, 2009.

23. Gerlach AT and Dasta JF: Dexmedetomidine: An updated review. Ann Pharmacother 41: 245-254, 2007.
24. Zhang X, He W, Wu X, Zhou X, Huang W and Feng X: TC remifentanil vs. TCI propofol for awake fiber-optic intubation with limited topical anesthesia. Int J Clin Pharmacol Ther 50: 10-16, 2012.

25. Drake LM, Chen SC and Rex DK: Efficacy of bispectral monitoring as an adjunct to nurse-administered propofol sedation for colonoscopy: A randomized controlled trial. Am J Gastroenterol 101: 2003-2007, 2006.

26. Grendelmeier P, Kurer G, Pflimlin E, Tamm M and Stolz D: Feasibility and safety of propofol sedation in flexible bronchoscopy. Swiss Med Wkly 141: w13248, 2011.

27. Gasparini S: It is time for patients to undergo bronchoscopy without discomfort. Eur Respir J 38: 507-509, 2011.

28. Jantz MA: The old and the new of sedation for bronchoscopy. Chest 135: 4-6, 2009.

29. Ebert TJ, Hall JE, Barney JA, Uhrich TD and Colinco MD: The effects of increasing plasma concentrations of dexmedetomidine in humans. Anesthesiology 93: 382-394, 2000.

30. Grant SA, Breslin DS, MacLeod DB, Gleason D and Martin G: Dexmedetomidine infusion for sedation during fiberoptic intubation: A report of three cases. J Clin Anesth 16: 124-126, 2004.

31. Deutsch E and Tobias JD: Hemodynamic and respiratory changes following dexmedetomidine administration during general anesthesia: Sevoflurane vs desflurane. Pediatr Anesth 17: 438-444, 2007.

32. Koroglu A, Teksan H, Sagir O, Yucel A, Toprak HI and Ersoy OM A comparison of the sedative, hemodynamic and respiratory effects of dexmedetomidine and propofol in children undergoing magnetic resonance imaging. Anesth Analg 103: 63-67, 2006.

33. Venn RM, Hell J and Grounds RM: Respiratory effects of dexmedetomidine in the surgical patient requiring intensive care. Crit Care 4: 302-308, 2000

34. Liao W, Ma G, Su QG, Fang Y, Gu BC and Zou XM: Dexmedetomidine vs. midazolam for conscious sedation in postoperative patients undergoing flexible bronchoscopy: A randomized study. J Int Med Res 40: 1371-1380, 2012.

35. Yoon HI, Kim JH, Lee JH, Park S, Lee CT, Hwang JY, Nahm SF and Han S: Comparison of propofol and the combination of propofol and alfentanil during bronchoscopy: A randomized study. Acta Anaesthesiol Scand 55: 104-109, 2011.

36. Adachi YU, Suzuki K, Obata Y, Doi M and Sato S: Is the hemodynamic response to nasotracheal fiberoptic bronchoscopy less than that following orotracheal bronchoscopy? Anesth Analg 105: 543, 2007.

37. Ryu JH, Lee SW,Lee JH, Lee EH, Do SH and Kim CS: Randomized double-blind study of remifentanil and dexmedetomidine for flexible bronchoscopy. Br J Anaesth 108: 503-511, 2012.

38. He XY, Cao JP, Shi XY and Zhang H: Dexmedetomidine vs. morphine or fentanyl in the management of children after tonsillectomy and adenoidectomy: A meta-analysis of randomized controlled trials. Ann Otol Rhinoly Laryngol 122: 114-120, 2013.

39. Hendrickx JF, Eger EI II, Sonner JM and Shafer SL: Is synergy the rule? A review of anesthetic interactions producing hypnosis and immobility. Anesth Analg 107: 494-506, 2008.

40. Piao G and Wu J: Systematic assessment of dexmedetomidine as an anesthetic agent: A meta-analysis of randomized controlled trials. Arch Med Sci 10: 19-24, 2014. 